\title{
Emerging Brominated Flame Retardants in the Sediment of the Great Lakes
}

\author{
Ruiqiang Yang, ${ }^{\dagger, \dagger}$ Hua Wei, ${ }^{\dagger}$ Jiehong Guo, ${ }^{\dagger}$ and An $\mathrm{Li}^{*}, \dagger$ \\ ${ }^{\dagger}$ School of Public Health, University of Illinois at Chicago, Chicago, Illinois 60612, United States \\ ${ }^{\ddagger}$ State Key Laboratory of Environmental Chemistry and Ecotoxicology, Research Center for Eco-Environmental Sciences, \\ Chinese Academy of Sciences, P.O. Box 2871, Beijing, 100085, China
}

Supporting Information

\begin{abstract}
The concentrations of 13 currently used brominated flame retardants (BFRs) were analyzed in 16 sediment cores collected from the North American Great Lakes. Among them, 1,2-bis(2,4,6-tribromophenoxy)ethane (BTBPE), decabromodiphenyl ethane (DBDPE), hexabromocyclododecane (HBCD), 1,2-dibromo-4-(1,2-dibromoethyl)cyclohexane (TBECH), and hexachlorocyclopentadienyl dibromocyclooctane (HCDBCO) were more frequently detected than others. In general, these emerging BFRs have much lower concentrations than polybromodiphenyl ethers (PBDEs) and dechloranes. Inventories of the five BFRs named above, given on a logarithm basis, were found to decrease linearly with the increasing latitude of the sampling locations, but with weaker statistics than those previously reported for the dechloranes. Logarithm of surface fluxes, on the other hand, was found to be a better parameter in correlating with the longitude. With regard to time trends,

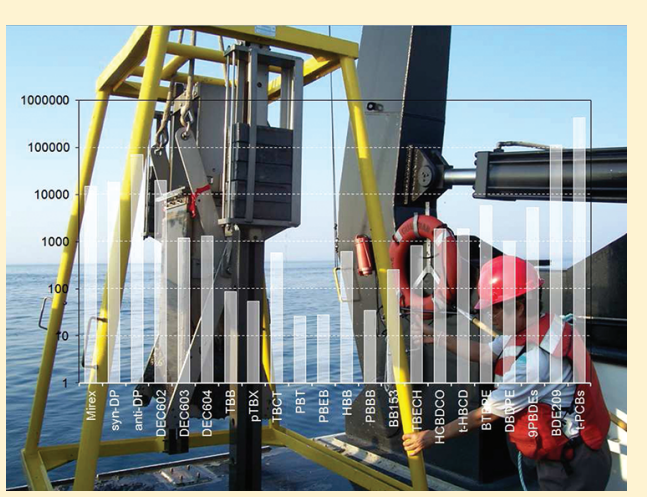
the exponential increases in concentrations of these BFRs, particularly DBDPE and BTBPE, in recent years are particularly disturbing. The sediment concentration of DBDPE doubles every 3-5 years in Lake Michigan, and approximately every 7 years in Lake Ontario. The corresponding doubling times for BTBPE are about 5 and 7 years in Lakes Ontario and Michigan, respectively, although declines or leveling off were observed in the top sediment layers in Lake Ontario. In contrast to PCBs, PBDEs, and most dechloranes, the correlations between the surface concentration of emerging BFRs and the latitude or longitude of the sampling sites were not strengthened by normalization of the concentration based on the organic matter content of the sediment.
\end{abstract}

\section{INTRODUCTION}

Because of the worldwide restrictive regulations on the manufacture and use of polybrominated diphenyl ethers (PBDEs), there is a growing market demand for nonregulated flame retardant alternatives. Compared with inorganic and phosphateor nitrogen-based organic flame retardants, brominated flame retardants (BFRs) have the advantages of low cost and high performance efficiency. ${ }^{1}$ At least 75 different BFRs were produced commercially in 2004. ${ }^{1}$ Many BFRs are on the U.S. EPA's High Production Volume ( $>454$ tonnes per year) chemical list or the Canadian Domestic Substance List $(>100 \mathrm{~kg}){ }^{2}$ Not surprisingly, the levels of some of these emerging BFRs in the environment have substantially increased in recent years.

This work is a continuation of our previous studies on persistent organic pollutants, including PBDEs, ${ }^{3-6} \mathrm{PCBs}^{7}$ and dechloranes, ${ }^{8}$ in the sediments of the Great Lakes of North America. A total of 13 BFRs of emerging concern were investigated (see Table S1 of the Supporting Information (SI) for their chemical structures). Five targeted BFRs are briefly introduced below.

1,2-Bis(2,4,6-tribromophenoxy)ethane (BTBPE or TBE) is produced and distributed under the trade name FF- 680 by Chemtura Corp. From 1986 to 1994, BTBPE was produced at rates of 4,500-22,500 tonnes per year, but production decreased to 450-4,500 tonnes per year after $1998 .^{9}$ Subsequently, production increased significantly to an estimated 16710 tonnes worldwide in $2001 .^{10}$ It has been announced as a potential replacement for octaBDE technical mixtures. ${ }^{11}$ BTBPE has been detected worldwide, including in the Arctic. ${ }^{10}$ In the Great Lakes region, BTBPE has been found in bird eggs ${ }^{1,12}$ and sediment cores from Lakes Ontario and Michigan. ${ }^{13,14}$ BTBPE levels in ambient air of the U.S. were found comparable to those of tetra- through hexa-PBDEs. ${ }^{13,15}$

Decabromodiphenyl ethane (DBDPE) is structurally similar to decabromodiphenyl ether (BDE209) and is marketed as an alternative for technical decaBDE. ${ }^{16}$ In the U.S., DBDPE has been manufactured since the early 1990s by Chemtura under the trade name Firemaster 2100 and by Albemarle under the trade name Saytex 8010. The aggregated production volume in 2006 was in the range of $4500-22500$ tonnes. ${ }^{17}$ Since the first report of DBDPE in the environment from Sweden in 2004, ${ }^{16}$

Received: November 19, 2011

Revised: February 8, 2012

Accepted: February 10, 2012

Published: February 10, 2012 
it has been detected in both near-source regions and remote area. ${ }^{18,19}$ Around the Great Lakes, DBDPE has been detected in air, ${ }^{15,20}$ tree bark, $^{21}$ and herring gulls eggs ${ }^{12}$ but not in the plasma of bald eagles. ${ }^{22}$ DBDPE is also among the pollutants that were not detected in Arctic ringed seals. ${ }^{23}$

Hexabromocyclododecane (HBCD), sold under the trade names Saytex HP-900 by Albermarle and Bromkal CD-75P by Chemtura, has the third highest global production volume among all BFRs. The world market demand for HBCD in 2003 was approximately 22000 tonnes, of which only $<20 \%$ was in the North America. ${ }^{10}$ The technical HBCD is a mixture of $\alpha, \beta$, and $\gamma$ stereoisomers, each being a pair of enantiomers, as well as two minor $\delta$ and $\varepsilon$ forms. HBCD is considered to have high bioaccumulation potential but low persistence. ${ }^{24}$ Nonetheless, HBCD has been found ubiquitously in all media, including air, biota, and sediment of the Arctic environment. ${ }^{10}$ In the Great Lakes region, HBCD was detected in bald eagle plasma, ${ }^{22}$ falcon nestlings, ${ }^{25}$ and the eggs of the herring gull. ${ }^{12}$ It was also found to biomagnify in the Lake Ontario pelagic food web. ${ }^{26}$

Four halogenated cyclohexanes are among the top 30 chemicals prioritized for environmental monitoring in North America. ${ }^{27}$ Among these halogenated cyclohexanes, 1,2dibromo-4-(1,2-dibromoethyl) cyclohexane (TBECH) is an additive flame retardant produced by Albemarle Corporation and sold as Saytex BCL-462. Its production most likely began before $1977 .{ }^{28}$ The aggregated production volume of TBECH in the U.S. was only 4.5 to 230 tonnes from 1986 to 2002 , which is much lower than those of other BFRs including BTBPE, DBDPE and HBCD. ${ }^{17}$ TBECH can exist as four pairs of enantiomers $(\alpha-, \beta$-, $\gamma$-, and $\delta$-TBECH). The $\alpha$ - and $\beta$-TBECH are the major components in technical products and present in a molar ratio of approximately $1: 1 .^{29} \mathrm{TBECH}$ has been detected in the Arctic environment, ${ }^{10,29}$ suggesting its potential for long-range atmospheric transport. In the Great Lakes region, TBECH is among other emerging BFRs found in eggs of herring gulls, ${ }^{11,12}$ but no previous report was found on the TBECH levels in the sediments.

Hexachlorocyclopentadienyl dibromocyclooctane (HCDBCO) contains both bromine and chlorine atoms in its molecule, and exists as a pair of enantiomers. It was patented as a flame retardant in $1975,{ }^{30}$ but no information on its manufacturer, trade name, or production and usage was found via literature search. It is, however, on the Canadian Nondomestic Substances List and the current priority chemical list of the California Biomonitoring Program. In 2008, the environmental presence of $\mathrm{HCDBCO}$ was first reported by $\mathrm{Zhu}$ et al. ${ }^{31}$ in indoor air and dust of Canadian homes, with concentrations generally lower than those of PBDEs and Dechlorane Plus (DP). However, HCDBCO was not detected in the fish of the Great Lakes, ${ }^{32}$ the indoor dust in Belgium and U.K., ${ }^{33}$ marine mammals in $\mathrm{Asia}^{34}$ and the seawater and atmosphere of the Atlantic Ocean. ${ }^{35}$

In addition to the five BFRs described above, other historical and emerging BFRs targeted in this work included hexabromobenzene (HBB), 1,3,5-tribromobenzene (TBB), pentabromoethylbenzene (PBEB), pentabromotoluene (PBT), tetrabromo-o-chlorotoluene (TBCT), pentabromobenzyl bromide (PBBB), 2,3,5,6-tetrabromo-p-xylene (pTBX), 2,2',4,4',5,5'hexabromobiphenyl (BB153), allyl 2,4,6- tribromo phenylether (ATE), and pentabromobenzyl acrylate (PBBA). Reviews of the sources and environmental levels are available in the literature for $\mathrm{HBB}, \mathrm{TBB}, \mathrm{PBEB}, \mathrm{PBT},{ }^{36,37}$ and $\mathrm{BB} 153 .^{38}$
Similar to our previous research, ${ }^{3-8}$ the objective of this work was to evaluate the current levels of contamination, examine the spatial distributions, reveal the chronology of input, and identify the factors influencing the accumulation of selected emerging BFRs in the Great Lakes sediment. Decabromodiphenyl ether (BDE209) was included for comparison purposes.

\section{EXPERIMENTAL SECTION}

Sampling. The 16 sampling locations are shown in Figure S1 of the Supporting Information, along with relevant information in SI Table S2. Most of these sites are in depositional zones where chemical input is likely to be dominated by atmospheric deposition. Sediment sampling was conducted from August 1 to 25,2007 , onboard of the EPA R/V Lake Guardian. Detailed methods of sampling, core sectioning, sample handling and characterization, and age dating, were published elsewhere. ${ }^{8}$ A total of 223 segment samples were obtained from the 16 cores.

Method Development. Presented in the Supporting Information are the chemicals purchased, sample pretreatment procedure, and methods of instrumental analyses. One of the major tasks in the method development was to obtain the elution order and the recoveries of all analytes from the silica gel cleanup column. The elution pattern of the analytes shown in SI Figure S2-A indicates that a $50 \mathrm{~mL}$ mixture of hexane and dichloromethane $(1: 1 \mathrm{v} / \mathrm{v})$ was sufficient to elute all analytes except PBBA and ATE. However, this solvent mixture was found to elute significant amounts of interfering substances, which interfered with gas chromatographic separation. The use of pure hexane resulted in the losses of relatively polar analytes, such as BTBPE and HBCD, in addition to PBBA and ATE (SI Figure S2-B). Comparatively, the use of a $70 \mathrm{~mL}$ mixture of hexane:dichloromethane $(5: 1, \mathrm{v} / \mathrm{v})$ was more effective at eluting target analytes, recovering $85 \%$ and $75 \%$ of BTBPE and HBCD, respectively, as shown in SI Figure S2-C. Therefore, $70 \mathrm{~mL}$ of $5: 1(\mathrm{v} / \mathrm{v})$ hexane:dichloromethane mixture was used for elution of the sediment samples.

In gas chromatography/mass spectrometry (GC/MS) analyses, challenges to the accurate quantification of the selected BFRs included the following. Two peaks were found for the TBECH standard (SI Figure S3-A) and the PBBB standard (SI Figure S3-B) in GC chromatograms for unknown reasons. In these cases, the total peak area was used, assuming equal response factors among isomers. For $\mathrm{HBCD}$, the $\alpha, \beta$ and $\gamma$ isomers could not be separated by the GC column (SI Figure $\mathrm{S} 3-\mathrm{C})$. Therefore, only the sum of the 3 isomers ( $t-H B C D)$ was determined. Interference in the analysis of BB153 was seen and was likely due to the presence of the coeluting $2,2^{\prime}, 4,4^{\prime}, 5$, 6'-hexabromodiphenyl ether (BDE154).

Detailed quality control measures and results are given in the Supporting Information. The average recoveries of the surrogates ${ }^{13} \mathrm{C}$-labeled decachlorobiphenyl (PCB209L) and native 2,4,6-tribromodiphenyl ether (BDE30) were $79.3 \pm 12.5 \%$ $(N=246)$ and $87.1 \pm 21.2 \%(N=108)$, respectively. The recovery of PCB209L was used to adjust the blank-subtracted concentrations. The method detection limit (MDL) was defined as 5 times the signal-to-noise $(\mathrm{s} / \mathrm{n})$ ratio. The MDLs were in the range of $0.001-0.005 \mathrm{ng} \mathrm{g}^{-1}$ (for TBCT and pTBX) to $0.03-0.16 \mathrm{ng} \mathrm{g}^{-1}$ (for DBDPE) with the use of 2$10 \mathrm{~g}$ samples. A Standard Reference Material of marine sediment (NIST 1941b) was analyzed using the same analytical procedure as for the sediment samples. The BDE209 concentration of 
Table 1. Range of Surface Concentrations of Selected BFRs by Lake ( $\mathrm{ng} \mathrm{g}^{-1} \mathrm{dw}$ )

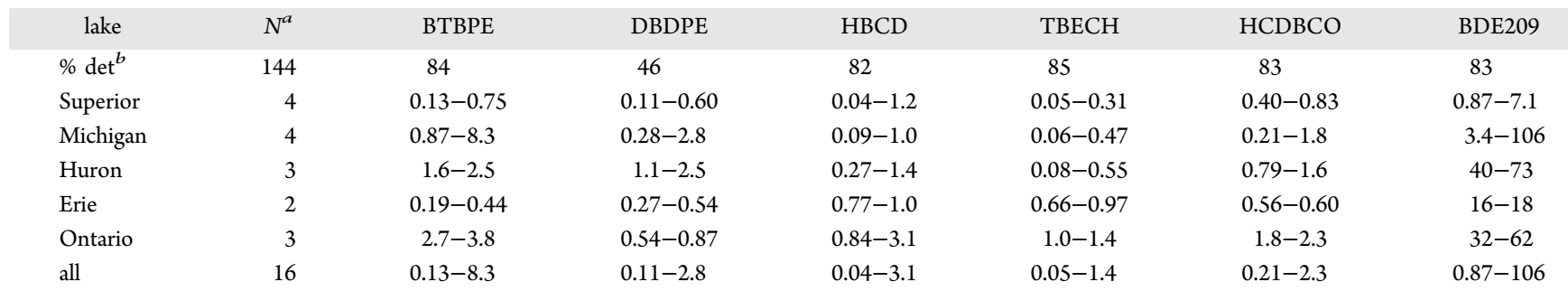

${ }^{a}$ Number of samples. ${ }^{b}$ Detection rate (\%) for samples dated 1950 or later.

$19.6 \mathrm{ng} / \mathrm{g} \mathrm{dw}$ found in NIST $1941 \mathrm{~b}$ is in satisfactory agreement with the $24.1 \mathrm{ng} / \mathrm{g}$ dw reported by Stapleton et al. ${ }^{39^{\circ}}$

\section{RESULTS AND DISCUSSION}

Of the 13 BFRs analyzed, BTBPE, DBDPE, HBCD, TBECH, and $\mathrm{HCDBCO}$ were more frequently detected than others, especially in recently deposited sediment segments. The ranges of their concentrations in surface sediments are presented in Table 1, and a comparison across sampling locations are given in SI Figure S4. The chemical inventory and input flux were estimated using methods established previously, ${ }^{3,8}$ and compared across locations in SI Figure S5. The concentrations are depicted in SI Figure S6 as a function of sediment depth, and the fluxes as a function of deposition year in SI Figure S7 for selected sites.

1,2-Bis(2,4,6-tribromophenoxy)ethane (BTBPE). BTBPE concentrations in the surface sediments are within the range of $0.13-8.3 \mathrm{ng} \mathrm{g}^{-1} \mathrm{dw}$ (Table 1). Our measurements of BTBPE in surface sediments are comparable with those previously observed in surface sediments from Michigan $\left(7.2 \mathrm{ng} \mathrm{g}^{-1} \mathrm{dw}\right)^{13}$ and Ontario $\left(6.7 \mathrm{ng} \mathrm{g}^{-1} \mathrm{dw}\right) .{ }^{14}$ Generally, the concentration of BTBPE decreases with increasing sediment depth, except in Lake Erie where zigzag patterns were observed as expected from the well-known sediment mixing in the lake (SI Figure S6). The highest BTBPE concentration, $9.0 \mathrm{ng} \mathrm{g}^{-1} \mathrm{dw}$, was observed at location LM-18 at the depth $0.5-1 \mathrm{~cm}$, which corresponds to the year $2001 .{ }^{4,8}$ On average, Lake Michigan has the highest surface concentration of BTBPE, followed by Lake Ontario. This is in clear contrast to the rank order for Dechloranes, of which the surface concentrations were significantly higher in Lake Ontario than in Lake Michigan. ${ }^{8}$

Similar to the previous findings for $\mathrm{PBDE},{ }^{6} \mathrm{PCBs}^{7}$ and dechloranes, $^{8}$ the inventory and surface flux of BTBPE decreased log-linearly with the increasing latitude and longitude, as illustrated in Figure 1. Regressions of logarithm surface concentration of BTBPE against latitude or longitude were found to be statistically insignificant ( $p>0.05$, SI Table S3). It is interesting to see that the surface flux is more statistically significantly correlated with the longitude $(p=0.008)$ than the inventory $(p=0.042)$. Closer examination of Figure 1 reveals that Lake Michigan sites (indicated by red points) receive higher BTBPE input than the correlation equations describe. The rank order of lakes in BTBPE accumulation is Michigan > Huron $>$ Ontario $>$ Erie > Superior, by comparing the lake average of inventories.

The chronological trends of BTBPE input flux to the Great Lakes sediment show that the input commenced in the 1970s at most sites (SI Figure S7). The increase of the input flux with time is exponential at some sites, following a first-order kinetic pattern (Figure 2). The doubling time $\left(t_{2}\right)$, calculated from the slope of the log-linear regressions, is about 6-7 years at sites in Lake Michigan and Lake Huron (LM-41, LM-47 and HU-12); but only about 5 years in Lake Ontario (Figure 2, SI Table S4). However, at most sites including all three sites in Lake Ontario, the input to the top sediment layers showed a decline or leveling off, from the peaks which appear to have occurred during the 1990s to early 2000s (SI Figure S7). Information on the production volume of BTBPE after 2001 is not available, making it difficult to explain the recent declines observed in the sediments. As the sale and use of BTBPE continue at this time, its input to the environment is expected to continue.

Decabromodiphenyl Ethane (DBDPE). DBDPE was detected in only $46 \%$ of all samples dated after 1950. This is the lowest detection rate among the five emerging BFRs discussed in this paper. The concentrations of DBDPE in the surface sediments ranged from 0.11 to $2.8 \mathrm{ng} \mathrm{g}^{-1} \mathrm{dw}$ and were lower than those of BTBPE and BDE209 (Table 1).

Concentrations of DBDPE show the same rank order of lakes as BTBPE, with Lakes Michigan and Huron being more contaminated than the other lakes (Table 1). However, both the inventory and the recent input flux of DBDPE correlates moderately with the latitude $(p=0.017)$, but insignificantly with the longitude $(p>0.05)$, of the sampling locations (Figure 1 and SI Table S3). In 11 isolated lakes in Sweden, significant correlation was also found between the sediment DBDPE concentration (ranging $0.23-11 \mathrm{ng} \mathrm{g}^{-1} \mathrm{dw}$ ) and the latitude of the locations. ${ }^{40}$

Despite the current low accumulation of DBDPE relative to PBDEs and BTBPE, the input of DBDPE has been rapidly increasing in recent years (SI Figure S7). The increase in DBDPE input flux in the last two decades is most rapid in Lake Michigan, where doubling times are estimated to be only 3 and 5 years at sites LM-41 and LM-47, respectively (Figure 2 and SI Table S4). In Lake Ontario, the increases are slightly slower with doubling times of approximately 6 and 7 years at ON-30 and ON-40, respectively. Even in Lake Erie where sediment mixing is severe, sharp increases in DBDPE concentration in the upper layers are obvious. At most sites, the increase of DBDPE input occurred around 1990 (SI Figure S7), or about 10-20 years later than that of BDE209. In contrast to BTBPE, the increase in DBDPE input is monotonic at most sites, with the highest concentration in the surface layer and no evidence of leveling off or decline in the recently deposited layers. The exceptions are LM-18, LM-47, SU-22, and ON-19, where a slight decrease in DBDPE input was observed at the surface sediment.

Hexabromocyclododecane (HBCD). The detection rate for $\mathrm{t}$-HBCD was $82 \%$ for samples dated 1950 or later. The surface concentration of $\mathrm{t}-\mathrm{HBCD}$ was in the range of 0.04 to $3.1 \mathrm{ng} \mathrm{g}^{-1} \mathrm{dw}$, and is comparable with the previously reported levels $\left(0.075-3.7 \mathrm{ng} \mathrm{g}^{-1} \mathrm{dw}\right)$ in the suspended sediments of the Detroit River. ${ }^{41}$ This range is also within the concentration 

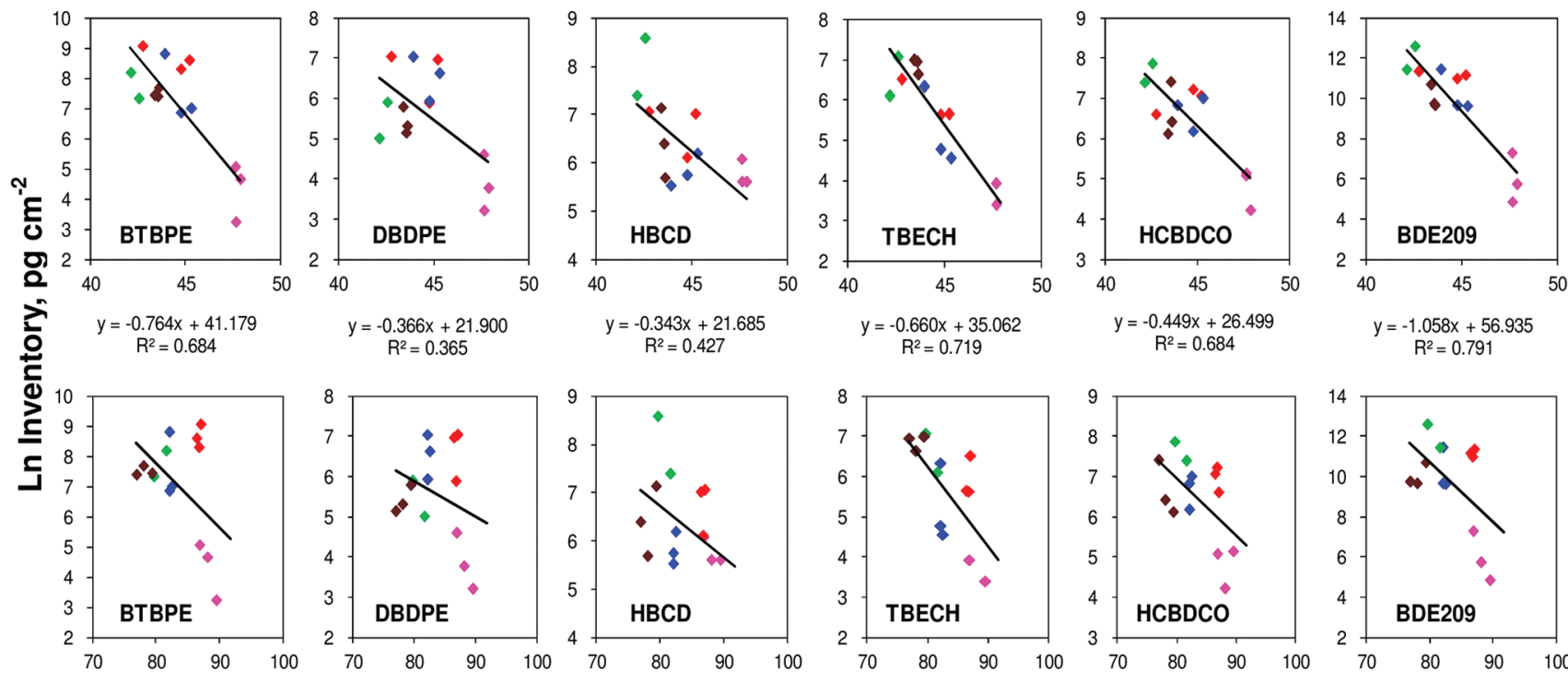

$y=-0.343 x+21.685$
$R^{2}=0.427$

$y=-0.660 x+35.062$
$R^{2}=0.719$

$R^{2}=0.684$

$\mathrm{R}^{2}=0.791$
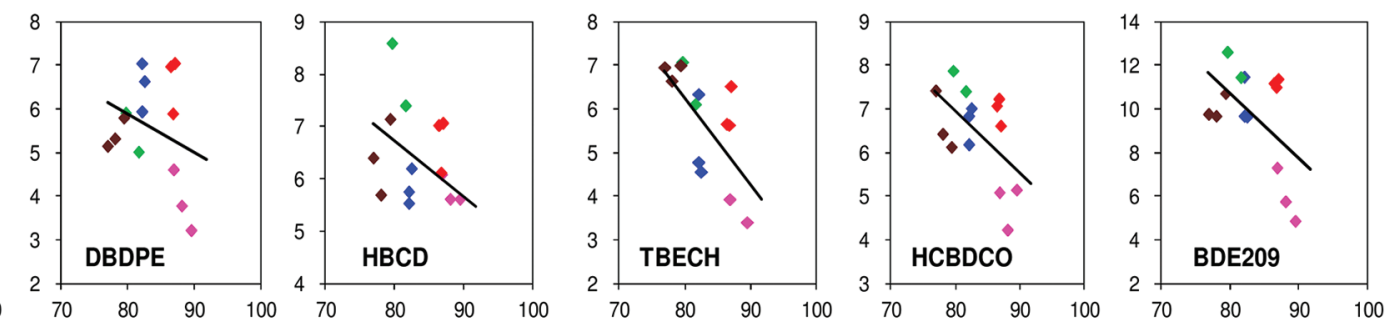

$y=-0.212 x+24.74$

$y=-0.087 x+12.827$

$y=-0.107 x+15.257$

$y=-0.198 x+22.115$

$R^{2}=0.347$
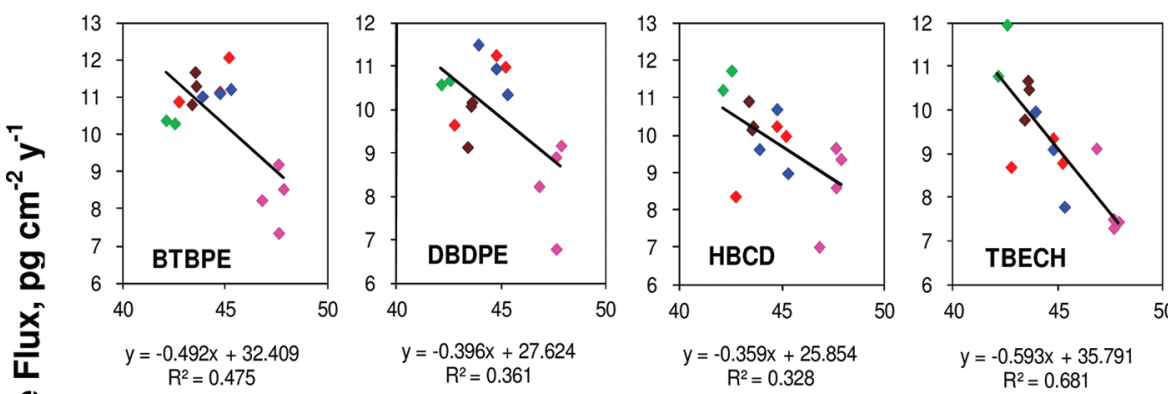

$y=-0.143 x+18.408$

$R^{2}=0.372$

$y=-0.298 x+34.545$

$R^{2}=0.335$
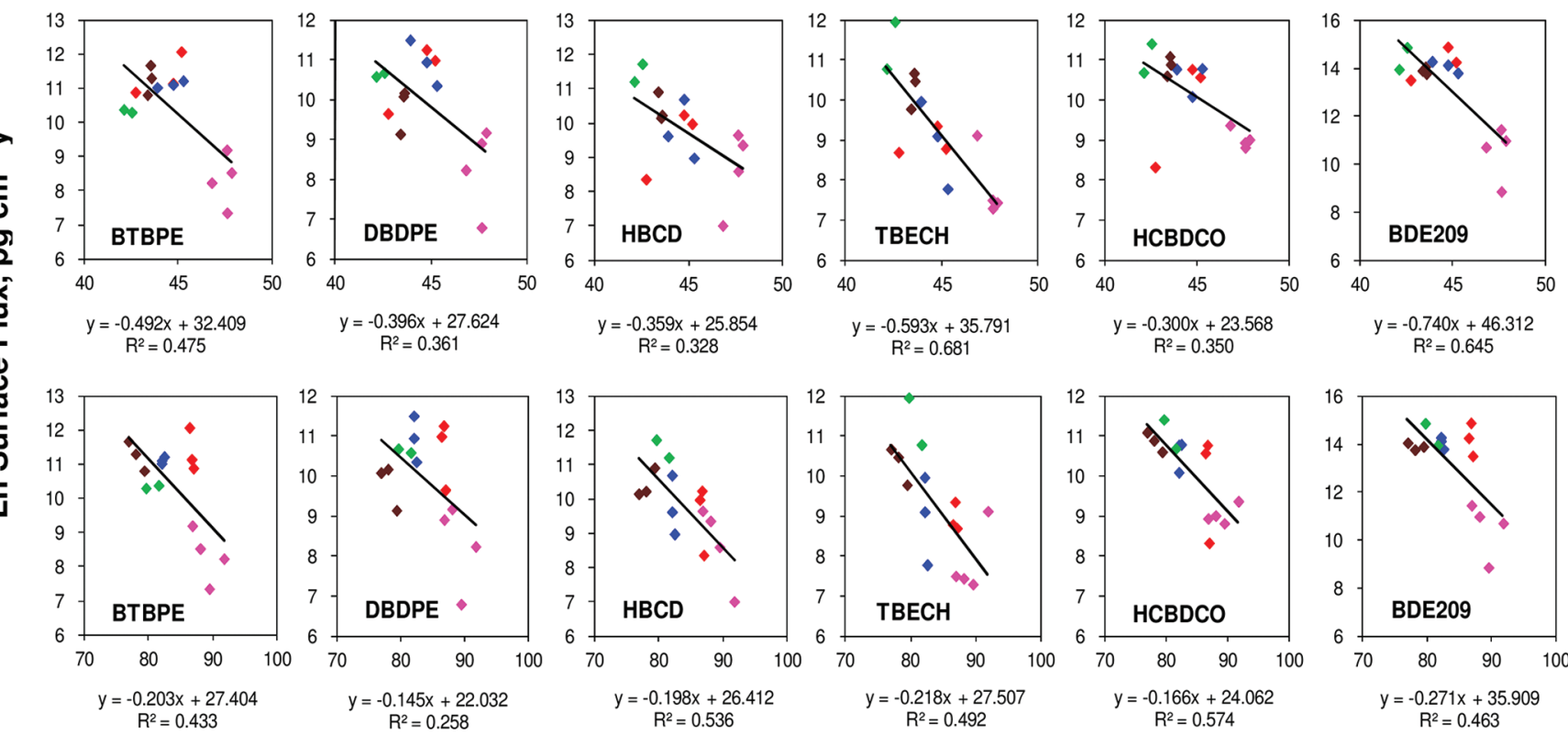

Lakes Superior • Michigan • Huron • Erie • Ontario

Figure 1. Dependence of inventory and surface flux on the latitude (N) (1st and 3rd rows) and longitude (W) (2nd and 4th rows) of the sampling locations for selected BFRs. Site LM-27 is excluded. Only sediment segments deposited later than 1950 are included. Detailed statistics for the regressions are given in Table S3 of the Supporting Information.

ranges $\left(<10 \mathrm{ng} \mathrm{g}^{-1} \mathrm{dw}\right)$ worldwide at locations dominated by diffuse sources, but orders of magnitude lower than those near point sources. ${ }^{42}$ Concentrations of HBCD are much lower than those of PBDEs in the Great Lakes sediments, ${ }^{24}$ in contrast to some cases in Europe where HBCDs were found at concentrations substantially higher than PBDEs. ${ }^{42}$

With regard to the spatial distribution of $\mathrm{HBCD}$, the logarithms of inventory correlated best with latitude and surface flux correlated best with longitude of the sampling locations (Figure 1 and SI Table S3). As expected, concentrations, either on a dry weight basis or OM normalized basis, were not statistically significantly correlated with the latitude and longtude of the sampling locations $(p>0.05)$ (SI Table S3). It is interesting that the two Lake Erie locations stand out as having significantly higher inventories and flux of HBCD than all other sites, especially at the east basin (ER-09) (SI Figure S5-A). The reason is not clear; the existence of a point source near ER-09 may not be excluded. Chronologically, HBCD appeared in the sediment around the mid 1980 s, and increased in nonmonotonic patterns in subsequent years (SI Figure S7). At most locations, a decrease in input flux was observed in the top sediment segments.

1,2-Dibromo-4-(1,2-dibromoethyl)cyclohexane (TBECH). In this work, the surface concentrations of TBECH were in the range of $0.05-1.4 \mathrm{ng} \mathrm{g}^{-1} \mathrm{dw}$, which are lower than those of BTBPE, DBDPE, and HBCD (Table 1) as expected from its lower production volume. $\mathrm{TBECH}$ input started 

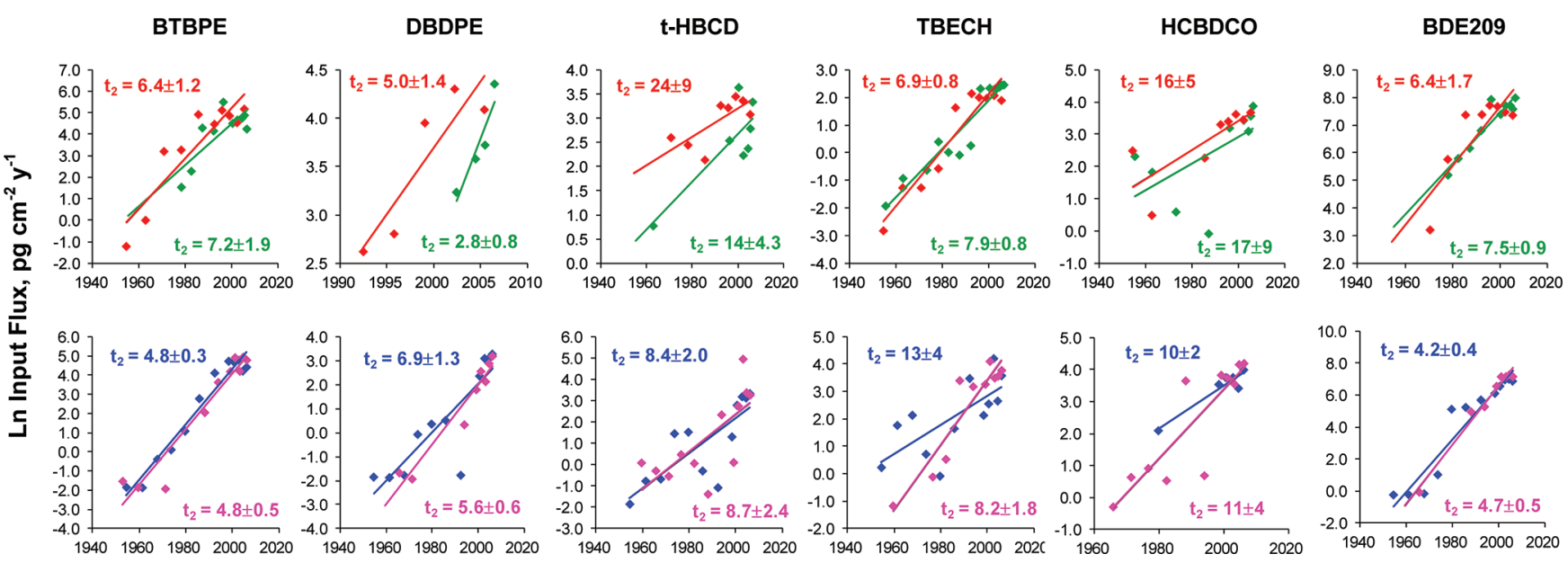

Figure 2. First-order kinetic plots of input flux to sediment for selected emerging BFRs at sampling sites LM-41 (green), LM-47 (red), ON-40 (blue), and ON-30 (pink). The doubling time $t_{2}$ (in years) was calculated using $t_{2}=\ln (2) /$ slope. The uncertainty of the $t_{2}$ values was estimated proportionally from the standard error of the slope. All the regressions are significant at $p<0.05$, with two exceptions (DBDPE and HCBDCO at LM-41).

approximately in the 1980 s at most locations. The Lake Erie site ER-09 appears to be a "hot spot," with a higher input rate and the shortest doubling time (4 years) among all sites (SI Table S4).

Again, the inventory is more significantly correlated with the latitude of the sampling locations than surface concentrations and flux (SI Table S3). Similar to the other emerging BFRs discussed above, the surface flux is more strongly related to longitude than concentrations and inventory (SI Table S3). Among the emerging BFRs discussed in this paper, TBECH is the only one for which the surface concentrations, either on dry weight basis or OM normalized basis, correlate statistically significantly with both the latitude and longitude (SI Table S3). To explain this, it is noticed that $\mathrm{TBECH}$ has lower molecular mass and likely higher vapor pressure compared with the other BFRs. This may render it a higher potential for long-range transport, and therefore air deposition may contribute more to sediment accumulation relative to local influences. Probably more important is that $\mathrm{TBECH}$ manufacturing commenced before 1977, earlier than the production starting dates for the other emerging BFRs and possibly concurrent with the PBDE production. Correlation with Dechlorane Plus was found to be significant for TBECH $(p<0.01)$, and is likely due to chronological similarity in production. No significant correlations with Dechlorane Plus were found for the other BFRs discussed in this paper.

The $\alpha$ and $\beta$ isomers were baseline separated with the $15 \mathrm{~m}$ GC column used in this work, allowing the examination of their ratio. The concentration ratio in all the samples had a median of 1.0 (ranging $0.02-24, N=152$ ), which is essentially the same as the ratio reported for the technical TBECH product. No trend was obvious when the isomer concentration ratio was plotted against sediment depth. Also, the inventory ratio of $\alpha / \beta$ isomers shows no trend with the latitude and longitude of the sampling sites $(N=16)$.

Hexachlorocyclopentadienyl Dibromocyclooctane (HCDBCO). The surface concentrations of HCBDCO were in the range of $0.21-2.3 \mathrm{ng} \mathrm{g}^{-1} \mathrm{dw}$, and were higher in Lake Ontario than in other lakes. Again, site ER-09 had a higher input rate and inventory than other sites (SI Figure S5). The correlations of the inventory and surface flux of $\mathrm{HCDBCO}$ with the latitude and longitude are statistically significant $(p<0.05)$, as shown in Figure 1 and SI Table S3.

The input flux of HCBDCO was generally increasing in recent years (Figure 2 and SI Figure S7). Rapid increases after 1980 were observed at most sites. The shortest doubling time of input flux, 5 years, was estimated for site HU-12 in Lake Huron; while in Lake Ontario, the doubling time was estimated to be 10-11 years (Figure 2).

Other BFRs. In addition to the 5 BFRs discussed above, other historical and emerging BFRs were included in the analyses. Among them, PBBA and ATE could not be quantified due to their low recoveries from the sample preparation procedures (SI Figure S2). For the others, their detection rates were all $<65 \%$ except $\mathrm{HBB}$ and TBCT, and their inventories at all sites were $<1 \mathrm{ng} \mathrm{cm}^{-2}$ except TBCT at two Lake Michigan sites and HBB at HU-12. The ranges of their surface concentrations are presented in SI Table S7.

Hexabromobenzene (HBB) was detected in $76 \%$ of all the samples. Site HU-12 was found to have $\mathrm{HBB}$ concentrations and inventory an order of magnitude higher than all other sites. Velsicol Chemical Corporation (formerly Michigan Chemical Corporation), located in St. Louis, Michigan, had been the HBB manufacturer in the region, before it was shut down in the 1980s. ${ }^{43}$ The heavily contaminated Pine River around the Velsicol plant may have carried HBB to the Saginaw Bay and thus, to Lake Huron. Although atmospheric transport may be more responsible for the widespread presence of HBB in Great Lakes sediment and herring gulls, ${ }^{11,12}$ none of the regressions of HBB levels in sediment against latitude and longitude is statistically significant. Little information is available for TBCT, which has recently been reported in sediments and suspended particulate matter in The Netherlands. ${ }^{44}$ In our study, TBCT was detected in most sediment layers dated after 1990, although interferences by unknown substances may have affected the quantitative analysis. The concentrations of TBB, pTBX, PBT, PBEB and PBBB were much lower than other targeted BFRs in this study (SI Table S7).

Comparison with BDE209. The analytical accuracy for BDE209 was found to be affected considerably by the efficiency of the sample cleanup and the instrument conditions. Particularly, discrepancies exist among previously reported concentration of BDE209 in Lake Ontario sediments. ${ }^{5,14}$ 
As shown in SI Table S5, the results of this work agree well with most literature data, yet confirm that the concentration in samples collected by this research group in 2002 are not as high as we previously reported. ${ }^{5,6}$ The use of acid silica gel in this study significantly improved chromatographic separation, compared with the cleanup method of Song et al. ${ }^{5}$ who used only neutral silica gel.

All of the emerging BFRs discussed above are at least 1 order of magnitude lower in concentration than BDE209 in the Great Lakes sediment. Using samples dated after 1950, the median ratios of BDE209 to BTBPE, DBDPE, HBCD, TBECH, and $\mathrm{HCBDCO}$ are 16, 51, 49, 88, and 42, respectively. Contamination of the sediment by the emerging BFRs is also much lower than that by the chlorinated flame retardant Dechlorane Plus. ${ }^{8}$ Figure 3 provides a comparison of the total

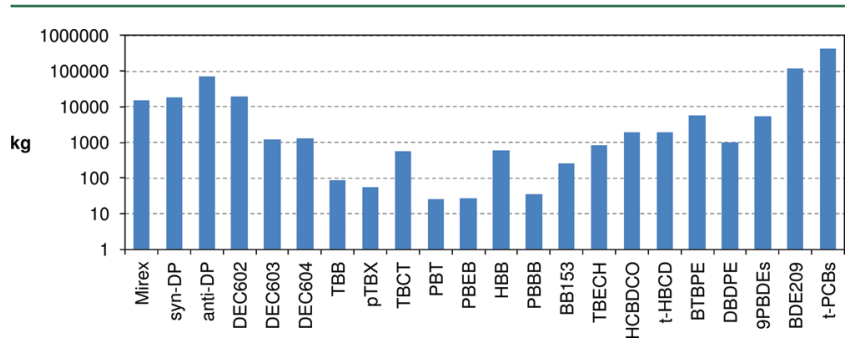

Figure 3. Comparison in total burden (load) among various halogenated chemical pollutants in the sediment of the Great Lakes. The total burden is the sum of the loads in individual lakes, which was estimated using: Total load $=$ average inventory $\times$ water surface area of the lake. Data are from refs 6-8 and this work. "9PBDEs" includes BDEs $28,66,47,85,99,100,153,154$, and 183 . Because of the limited number of sampling spots, this comparison should be used with caution.

burden among various halogenated chemical pollutants in the Great Lakes sediments. Pearson's correlation analysis indicated the general lack of correlations between the Dechloranes (except Dec604) reported previously ${ }^{8}$ and the BFRs of this work (except TBECH). The spatial pattern of Dechloranes is largely driven by a point source near the Niagara River, $8,14,45,46$ while the distributions of the emerging BFRs are not. With the major U.S. manufacturing facilities of BFRs located in southern Arkansas, the BFRs found in the Great Lakes could originate from wide variety of flame-retarded commercial products, which constitute the urban-centered diffusive sources.

Pearson's correlations between BFR concentrations for each lake are summarized in SI Table S6. In Lakes Michigan and Ontario, concentrations for all the BFRs were significantly $(p<$ 0.01 ) correlated with each other, suggesting that, in general, these BFRs come from similar sources and/or share similar input chronology in the region. The lack of correlation among some BFRs in the relatively remote Lake Superior may relate to the low concentrations or imply differences in long-range transport potential. Concentrations of BFRs in Lake Erie, however, showed the least correlation due to the extensive sediment mixing.

Finally, unlike the cases of PBDEs, ${ }^{6} \mathrm{PCBs}^{7}$ and all dechloranes except Dec603, ${ }^{8}$ normalization of the dry weight based concentrations of the selected emerging BFRs by the sediment organic matter (OM) content does not strengthen the correlations of concentration with the latitude and longitude of the sampling sites (SI Table S3). In other words, the region-wide spatial distribution patterns of the emerging BFRs in sediments may be dominated by the locations of their sources and other factors. The physicochemical properties of the sediment itself, of which the OM content is among the most influential to the retention of trace hydrophobic organics, play insignificant roles in affecting the spatial distribution, at least at the present time. This observation can be related to the much lower levels of the contamination and shorter time of accumulation compared with PBDEs, PCBs, and dechloranes.

\section{ASSOCIATED CONTENT}

\section{Supporting Information}

Materials, laboratory methods, and quality control procedures, as well as additional tables and figures. This material is available free of charge via the Internet at http://pubs.acs.org.

\section{AUTHOR INFORMATION}

\section{Corresponding Author}

*E-mail: anli@uic.edu. Tel: +1 312-996-9597. Fax: +1 312-4139898.

Notes

The authors declare no competing financial interest.

\section{ACKNOWLEDGMENTS}

We thank the Captain and crew of the R/V Lake Guardian for the assistance in sampling. This research was supported by funding from the Great Lakes National Program Office (GLNPO), the U.S. Environmental Protection Agency, with Assistance \# GL-00E27901 (Program Officer Todd Nettesheim).

\section{REFERENCES}

(1) Birnbaum, L. S.; Staskal, D. F. Brominated flame retardants: cause for concern? Environ. Health Perspect. 2004, 112, 9-17.

(2) Howard, P. H.; Muir, D. C. G. Identifying new persistent and bioaccumulative organics among chemicals in commerce. Environ. Sci. Technol. 2010, 44, 2277-2285.

(3) Song, W. L.; Ford, J. C.; Li, A.; Mills, W. J.; Buckley, D. R.; Rockne, K. J. Polybrominated diphenyl ethers in the sediments of the Great Lakes. 1. Lake Superior. Environ. Sci. Technol. 2004, 38, 32863293.

(4) Song, W. L.; Li, A.; Ford, J. C.; Sturchio, N. C.; Rockne, K. J.; Buckley, D. R.; Mills, W. J. Polybrominated diphenyl ethers in the sediments of the Great Lakes. 2. Lakes Michigan and Huron. Environ. Sci. Technol. 2005, 39, 3474-3479.

(5) Song, W. L.; Ford, J. C.; Li, A.; Sturchio, N. C.; Rockne, K. J.; Buckley, D. R.; Mills, W. J. Polybrominated diphenyl ethers in the sediments of the Great Lakes. 3. Lakes Ontario and Erie. Environ. Sci. Technol. 2005, 39, 5600-5605.

(6) Li, A.; Rockne, K. J.; Sturchio, N.; Song, W.; Ford, J. C.; Buckley, D. R.; Mills, W. J. Polybrominated diphenyl ethers in the sediments of the Great Lakes. 4. Influencing factors, trends, and implications. Environ. Sci. Technol. 2006, 40, 7528-7534.

(7) Li, A.; Rockne, K. J.; Sturchio, N.; Song, W.; Ford, J. C.; Wei, H. PCBs in sediments of the Great Lakes: Distribution and trends, homolog and chlorine patterns, and in situ degradation. Environ. Pollut. 2009, 157, 141-147.

(8) Yang, R. Q.; Wei, H.; Guo, J. H.; McLeod, C.; Li, A.; Sturchio, N. C. Historically and currently used Dechloranes in the sediments of the Great Lakes. Environ. Sci. Technol. 2011, 45, 5156-5163.

(9) Chemtura 2011. Brominated Flame Retardants http://www. chemtura.com $/ \mathrm{bu} / \mathrm{v} /$ index.jsp? vgnextoid $=\mathrm{df5} 58 \mathrm{~d} 843400 \mathrm{c} 110 \mathrm{Vgn}-$ VCM10000053d7010aRCRD\&vgnextchannel=df5e8d843400c110VgnVCM10000053d7010aRCRD\&vgnextfmt $=$ default (accessed in Jan. 2011). 
(10) de Wit, C. A.; Herzke, D.; Vorkamp, K. Brominated flame retardants in the Arctic environment: trends and new candidates. Sci. Total Environ. 2010, 408, 2885-2918.

(11) Gauthier, L. T.; Potter, D.; Hebert, C. E.; Letcher, R. J. Temporal trends and spatial distribution of non-polybrominated diphenyl ether flame retardants in the eggs of colonial populations of Great Lakes Herring Gulls. Environ. Sci. Technol. 2009, 43, 312-317.

(12) Gauthier, L. T.; Hebert, C. E.; Weseloh, D. V. C.; Letcher, R. J. Current-use flame retardants in the eggs of Herring Gulls (Larus argentatus) from the Laurentian Great Lakes. Environ. Sci. Technol. 2007, 41, 4561-4567.

(13) Hoh, E.; Zhu; Hites, R. A. Novel flame retardants, 1,2-Bis (2,4,6tribromophenoxy)ethane and 2,3,4,5,6-pentabromoethylbenzene, in United States' environmental samples. Environ. Sci. Technol. 2005, 39, 2472-2477.

(14) Qiu, X.; Marvin, C. H.; Hites, R. A. Dechlorane plus and other flame retardants in a sediment core from Lake Ontario. Environ. Sci. Technol. 2007, 41, 6014-6019.

(15) Salamova, A.; Hites, R. A. Discontinued and alternative brominated flame retardants in the atmosphere and precipitation from the Great Lakes Basin. Environ. Sci. Technol. 2011, 45, 86988706.

(16) Kierkegaard, A.; Bjorklund, J.; Friden, U. Identification of the flame retardant decabromodiphenyl ethane in the environment. Environ. Sci. Technol. 2004, 38, 3247-3253.

(17) Non-confidential IUR Production Volume Information. http:// cfpub.epa.gov/iursearch/2006_iur_companyinfo.cfm? chemid= 6524\&outchem=both (accessed on April 14, 2011).

(18) Zhang, X. L.; Luo, X. J.; Chen, S. J.; Wu, J. P.; Mai, B. X. Spatial distribution and vertical profile of polybrominated diphenyl ethers, tetrabromobisphenol $\mathrm{A}$, and decabromodiphenylethane in river sediment from an industrialized region of South China. Environ. Pollut. 2009, 157, 1917-1923.

(19) Hermanson, M. H.; Isaksson, E.; Forsström, M. S.; Teixeira, C.; Muir, D. C. G.; Pohjola, V. A.; van de Wal, R. S. V. Deposition history of brominated flame retardant compounds in an ice core from Holtedahlfonna, Svalbard, Norway. Environ. Sci. Technol. 2010, 44, $7405-7410$.

(20) Venier, M.; Hites, R. A. Atmospheric deposition of PBDEs to the Great Lakes featuring a Monte Carlo analysis of errors. Environ. Sci. Technol. 2008, 42, 9058-9064.

(21) Qiu, X.; Hites, R. A. Dechlorane plus and other flame retardants in tree bark from the northeastern United States. Environ. Sci. Technol. 2007, 42, 31-36.

(22) Venier, M.; Wierda, M.; Bowerman, W. W.; Hites, R. A. Flame retardants and organochlorine pollutants in bald eagle plasma from the Great Lakes region. Chemosphere 2010, 80, 1234-1240.

(23) Muir, D.; Kwan, M.; Evans, M. Temporal trends of persistent organic pollutants and metals in ringed seals from the Canadian Arctic. In Synopsis of Research Conducted under the 2006-2007 Northern Contaminants Program; : Smith, S, Stow, J, Eds.; Indian Affairs and Northern Development: Ottawa, ON, Canada, 2007; pp 211-218.

(24) U.S. EPA Supporting documents for initial risk-based prioritization of high production volume chemicals: hexabromocyclododecane (HBCD) http://www.epa.gov/chemrtk/hpvis/rbp/HBCD. 3194556.Web.SupportDocs.31408.pdf (accessed on July 14, 2011).

(25) Fernie, K. J.; Letcher, R. J. Historical contaminants, flame retardants, and halogenated phenolic compounds in Peregrine Falcon (Falco peregrinus) nestlings in the Canadian Great Lakes Basin. Environ. Sci. Technol. 2010, 44, 3520-3526.

(26) Tomy, G. T.; Budakowski, W.; Halldorson, T.; Whittle, D. M.; Keir, M. J.; Marvin, C.; MacInnis, G.; Alaee, M. Biomagnification of alpha- and gamma-hexabromocyclododecane isomers in a Lake Ontario food web. Environ. Sci. Technol. 2004, 38, 2298-2303.

(27) Howard, P. H.; Muir, D. C. G. Are there other persistent organic pollutants? A challenge for Environmental Chemists. Environ. Sci. Technol. 2006, 40, 7157-7166.
(28) U.S. EPA. 1,2-Dibromo-4-(1,2-dibromoethyl)cyclohexane (TBEC) Test Results: ITC designations 14th report. Federal Register, U.S. Government Printing Office: Washington, DC, 1984; 49 FR 22389.

(29) Tomy, G. T.; Pleskach, K.; Arsenault, G.; Potter, D.; McCrindle, R.; Marvin, C. H.; Sverko, E.; Tittlemier, S. Identilication of the novel cycloaliphatic brominated flame retardant 1,2-dibromo-4-(1,2dibromoethyl)cyclohexane in Canadian Arctic beluga (Delphinapterus leucas). Environ. Sci. Technol. 2008, 42, 543-549.

(30) Riddell, N.; Arsenault, G.; Lough, A.; McAlees, A.; McCrindle, R; Meissner, J.; Robertson, V. The three-dimensional structural characterization of hexachlorocyclopentenyl- dibromocyclooctane (HCDBCO). Chemosphere 2008, 73, 479-483.

(31) Zhu, J.; Hou, Y.; Feng, Y. L.; Shoeib, M.; Harner, T. Identification and determination of hexachlorocyclopentadienyldibromocyclooctane (HCDBCO) in residential indoor air and dust: A previously unreported halogenated flame retardant in the environment. Environ. Sci. Technol. 2008, 42, 386-391.

(32) Zhou, S. N.; Reiner, E. J.; Marvin, C.; Kolic, T.; Riddell, N.; Helm, P.; Dorman, F.; Misselwitz, M.; Brindle, I.D. Liquid chromatography-atmospheric pressure photoionization tandem mass spectrometry for analysis of 36 halogenated flame retardants in fish. J. Chromatogr. A 2010, 1217, 633-641.

(33) Ali, N.; Harrad, S.; Muenhor, D.; Neels, H.; Covaci, A. Analytical characteristics and determination of major novel brominated flame retardants (NBFRs) in indoor dust. Anal. Bioanal. Chem. 2011, 400, 3073-3083.

(34) Lam, J. C. W.; Lau, R. K. F.; Murphy, M. B.; Lam, P. K. S. Temporal trends of hexabromocyclododecanes (HBCDs) and polybrominated diphenyl ethers (PBDEs) and detection of two novel flame retardants in marine mammals from Hong Kong, South China. Environ. Sci. Technol. 2009, 43, 6944-6949.

(35) Xie, Z.; Moeller, A.; Ahrens, L.; Sturm, R.; Ebinghaus, R. Brominated flame retardants in seawater and atmosphere of the Atlantic and the Southern Ocean. Environ. Sci. Technol. 2011, 45, $1820-1826$.

(36) Covaci, A.; Harrad, S.; Abdallah, M. A. E.; Ali, N.; Law, R. J.; Herzke, D.; de Wit, C. A. Novel brominated flame retardants: A review of their analysis, environmental fate and behavior. Environ. Inter. 2011, $37,532-556$.

(37) de Wit, C. A.; Kierkegaard, A.; Ricklund, N.; Sellström, U. Emerging Brominated Flame Retardants in the Environment. In: The Handbook of Environmental Chemistry; Eljarrat, E., Barceló, D., Eds.; Springer: Berlin, 2011; pp 241-286.

(38) ATSDR. Toxicological Profile for Polybrominated Biphenyls and Polybrominated Diphenyl Ethers; Agency for Toxic Substances and Disease Registry, U.S. Department of Health and Human Services: Washington, DC, 2004; http://www.atsdr.cdc.gov/substances/ toxsubstance.asp?toxid=94 (accessed May 29, 2006).

(39) Stapleton, H. M.; Keller, J. M.; Schantz, M. M.; Kucklick, J. R.; Leigh, S. D.; Wise, S. A. Determination of polybrominated diphenyl ethers in environmental standard reference materials. Anal. Bioanal. Chem. 2007, 387, 2365-2379.

(40) Ricklund, N.; Kierkegaard, A.; McLachlan, M. S. Levels and potential sources of decabromodiphenyl Ethane (DBDPE) and decabromodiphenyl ether (DecaBDE) in lake and marine sediments in Sweden. Environ. Sci. Technol. 2010, 44, 1987-1991.

(41) Marvin, C. H.; Tomy, G. T.; Alaee, M.; MacInnis, G. Distribution of hexabromocyclododecane in Detroit River suspended sediments. Chemosphere 2006, 64, 268-275.

(42) Covaci, A.; Gerecke, A. C.; Law, R. J.; Voorspoels, S.; Kohler, M.; Heeb, N. V.; Leslie, H.; Allchin, C. R.; de Boer, J. Hexabromocyclododecanes (HBCDs) in the environment and humans: a review. Environ. Sci. Technol. 2006, 40, 3679-3688.

(43) U.S. EPA. Region Five Superfund, Velsicol Chemical Company. http://www.epa.gov/R5Super/npl/michigan/MID000722439.htm (accessed on $5 / 21 / 2008$ ).

(44) López, P.; Brandsma, S. A.; Leonards, P. E. G.; de Boer, J. Optimization and development of analytical methods for the determination of new brominated flame retardants and polybromi- 
nated diphenyl ethers in sediments and suspended particulate matter. Anal. Bioanal. Chem. 2011, 400, 871-883.

(45) Hoh, E.; Zhu; Hites, R. A. Dechlorane plus, a chlorinated flame retardant, in the Great Lakes. Environ. Sci. Technol. 2006, 40, 11841189.

(46) Sverko, E.; Tomy, G. T.; Marvin, C. H.; Zaruk, D.; Reiner, E.; Helm, P. A.; Hill, B.; McCarry, B. E. Dechlorane plus levels in sediment of the lower Great Lakes. Environ. Sci. Technol. 2008, 42, 361-366. 